\title{
Effect of precipitate size distribution on hardness of aluminium 6063 alloy
}

\author{
LWUR Dilrukshi" and GIP De Silva \\ Department of Materials Science and Engineering, Faculty of Engineering, University of Moratuwa, Moratuwa.
}

Submitted: 11 October 2019; Revised: 31 March 2020; Accepted: 29 May 2020

\begin{abstract}
In this study, the effects of precipitate size and size distribution on the hardness of $\mathrm{Al} 6063$ alloy were examined. Al 6063 samples were subjected to a solution treatment at $530{ }^{\circ} \mathrm{C}$ for 4 hours and quenched in water followed by storing in freezer $\left(-18{ }^{\circ} \mathrm{C}\right)$ to prevent natural ageing. Ageing treatment was done at $190{ }^{\circ} \mathrm{C}$ for $135,180,225,270$ and 315 minutes. Precipitates distributed in the matrix were identified as Fe-Sirich and $\mathrm{Fe}-\mathrm{Si}-\mathrm{Mg}$-rich precipitates by performing Scanning Electron Microscope/Energy Dispersive Spectroscopy (SEM/ EDS) analysis. Number of precipitates, average size and the area covered by precipitates were calculated by Image $\mathrm{J}$ software based on the precipitates observed in SEM images. For all heating profiles, precipitate size was less than $3.2 \mu \mathrm{m}$. Maximum hardness of $143.90 \mathrm{HV}$ was achieved for 270-minutes ageing time. A significant decrease in hardness was evident when the particles were coarsening above $1.5 \mu \mathrm{m}$, possibly due to overageing for ageing time beyond $270 \mathrm{~min}$.
\end{abstract}

Keywords: Age hardening, Al 6063 alloy, hardness, precipitate size distribution.

\section{INTRODUCTION}

Aluminium ( $\mathrm{Al})$ is the most abundant metal on the Earth crust containing $8 \%$ of the weight of the Earth's solid surface. Aluminium 6063 alloy consists of Mg (0.45$0.90 \mathrm{wt} \%)$ and $\mathrm{Si}(0.2-0.6 \mathrm{wt} \%)$ as its major alloy elements (Couper et al., 2010). It is extensively used for structural applications such as partitioning, windows, door frames, ladders and bars of varying cross-sections. In addition, it has been identified as a marine grade alloy because of its excellent corrosion resistance in marine environments. The high strength-to-weight ratio has made it very attractive to aviation and automobile industries as well. Its corrosion resistance, high strength and excellent extrudability make it an excellent structural material.

Al 6063 alloy has been subjected to a precipitation hardening treatment to improve its hardness and strength up to a required level that is dependent on the components to be produced (Cavazos \& Colãs, 2003). Thus, wide-ranging knowledge regarding evolution of microstructure during precipitation hardening and their effect on mechanical properties are critically focused in previous research (Cavazos \& Colãs, 2003; Nandy et al., 2015). Current research on precipitation hardening of Al 6063 alloy have studied the effect of chemical composition and heat treatment profile either individually or in combination to gain the required level of strength and hardness. Yildirim \& Özyürek (2013) found the effect of magnesium content on the strength and hardness of Al 6063 alloy.

The quench sensitivity of aluminium alloys has been studied by Cavazos \& Colãs (2003). The study concluded that final hardness was sensitive only for cooling rate lower than $10{ }^{\circ} \mathrm{C} / \mathrm{s}$ after solution treatment due to incipient precipitation. Li et al. (2013) repeated the same experiments using a salt bath instead of water as the quenching medium and found that the critical temperature range of $410-300{ }^{\circ} \mathrm{C}$ is more susceptible for incipient precipitation. This is an important result for the

"Corresponding author (dilrukshiur80@gmail.com; (10) https://orcid.org/0000-0003-2531-9483) 
aluminium extrusion industry as cooling rate needs to be controlled specially within the above temperature range.

Siddiqui et al. (2000) studied the ranges of age hardening process parameters and their combinations to obtain the different sets of tensile strength, yield strength and hardness. The best combination in terms of applications - tensile strength $(150 \mathrm{MPa})$, yield strength (140 MPa) and hardness (68 RB), was obtained at $175^{\circ} \mathrm{C}$ for 8-10 hour ageing time.

Precipitates/particles strengthen the alloy by acting as obstacles to dislocation motion by 'cutting through (shearing)' and 'bowing and bypassing' mechanisms (Kulkarni et al., 2004).

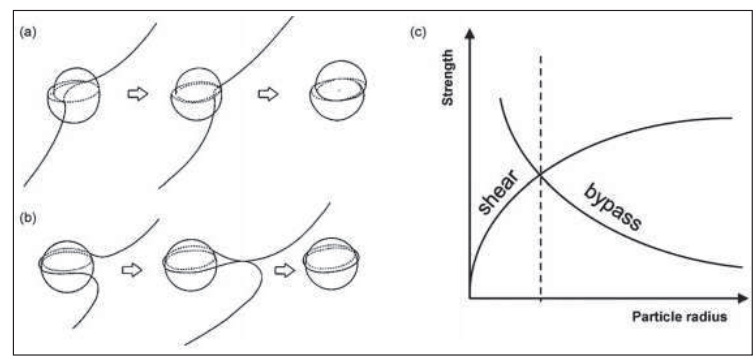

Figure 1: Schematic illustration of (a) cutting through and (b) bowing and bypassing; (c) relationship between strength vs precipitate radius (Sjölander \& Seifeddine, 2010)

There is an elastic stress existing in the matrix around the precipitate due to difference lattice parameter relative to the matrix area, especially at the early stage of precipitation where particles are smaller and less hard. Under this condition, metal hardening would predominantly occur by cutting through mechanism. In addition, coherency and modulus hardening and, chemical and ordering strengthening contribute to the hardening of metal matrix (Guo \& Sha,2005). For a longer ageing time, inter-particle space is increased in resulting coarsening of precipitates; this condition leads to the bowing and bypass mechanism.

According to previous research (Jacobs, 1999; Kulkarni et al., 2004) cutting through mechanism significantly affect increasing the hardness relative to the bowing and bypassing. However, bowing and bypassing associated with coarser particles make the structure more brittle while reducing the hardness and strength. This phenomenon is schematically illustrated in Figure 1.
The degree of strengthening is determined by the particle size, size distribution as well as inter-particle spacing. In this work, all types of precipitates distributed in the matrix (solid solution) are considered as the second phase and that is denoted as $\beta$. Research (Gao et al., 2009; Lillywhite et al., 2012; Asensio-Lozano et al., 2014) has shown that cutting through mechanism becomes predominant with higher percentage of particles in the size range of $R_{1}(0.00-0.2 \mu \mathrm{m})$ and bowing and bypassing mechanism becomes predominant within the particle size range of $\mathrm{R}_{2}(0.2-1.5 \mu \mathrm{m})$. Further, they have shown that both mechanisms could be activated within the range of $\mathrm{R}_{2}(0.2-1.5 \mu \mathrm{m})$.

Research has been carried out regarding dislocation interaction with precipitate obstacles in age hardened Al alloys through computational simulations. For a given ageing temperature, increasing the average radius of precipitates while maintaining constant volume fraction would initially increase the strength to maximum followed by a diminishing in strength (over-ageing) (Mohles et al., 1999). This type of system follows the Ostwald Ripening behaviour. The larger particles (energetically favoured) were grown further by dissolving small particles while minimizing the total area covered by precipitates. In 1958, Lifshitz and Slyozov derived a mathematical model for such a system to evaluate the distribution of the particle radii, presently known as LWS theory.

Mechanical properties after application of ageing treatment depend on the size and size distribution of the precipitates being formed, which depends on processed time and temperature (Cavazos \& Colãs, 2003). This work is focused on studying the variation of hardness of Al 6063 alloy with the precipitate size distribution in different size ranges, under the increase of ageing time.

\section{METHODOLOGY}

Original Al 6063 alloy samples homogenised at $570{ }^{\circ} \mathrm{C}$ for $2.5 \mathrm{~h}$ were obtained from a local $\mathrm{Al}$ products manufacturing company. Chemical analysis was performed by spark emission spectrometer to assure the chemical composition and results are shown in Table 1.

Table 1: Chemical analysis of Al 6063 alloy

\begin{tabular}{lccccccc}
\hline Element & $\mathrm{Si}$ & $\mathrm{Mg}$ & $\mathrm{Fe}$ & $\mathrm{Cu}$ & $\mathrm{Mn}$ & $\begin{array}{c}\text { Other Minor } \\
\text { Elements }\end{array}$ & $\mathrm{Al}$ \\
\hline Wt. \% & 0.42 & 0.47 & 0.53 & 0.01 & 0.02 & 0.25 & 98.3 \\
\hline
\end{tabular}


Samples having the size of $20 \mathrm{~mm} \times 20 \mathrm{~mm} \times 10 \mathrm{~mm}$ were used for the heat treatment process. The samples were subjected to a solution treatment for $4 \mathrm{~h}$ at $530{ }^{\circ} \mathrm{C}$ in a programmable muffle furnace, followed by quenching in water. The quenched samples were immediately transferred to freezer $\left(-18{ }^{\circ} \mathrm{C}\right)$ to avoid natural ageing at room temperature (Siddiqui et al., 2000). Ageing was done at $190{ }^{\circ} \mathrm{C}$ for $135,180,225,270$ and $315 \mathrm{~min}$ in the same furnace. Two samples were heat treated for each ageing time mentioned above. Vickers hardness was performed as per ASTM E92 ( $5 \mathrm{kgf}$, loading speed $70 \mu \mathrm{m} / \mathrm{s}$, time $15 \mathrm{~s}$ ) and hardness values were calculated by taking the average of five readings for each ageing time.

Specimens having the dimensions of $10 \mathrm{~mm} \times 10 \mathrm{~mm}$ $\times 10 \mathrm{~mm}$ were made by using ISOMET Low Speed Saw (oil cutting) and those were cleaned with ethanol (10 min) using ultrasonic cleaner. These specimens were used for the SEM/EDS analysis to ensure the particle types in terms of chemical composition. Observations were performed under BSD mode with current-100 $\mu \mathrm{A}$, EHT-20 KV and $\times 5000$ magnifications. Images were captured using four specimens belonging to each ageing time and 10 different areas were randomly selected from each specimen to provide a sufficient graphical characterisation for precipitates distribution. These image sets were analysed using Image $J$ software to calculate the number of precipitates, average size and area covered by precipitates. Percentage of precipitates belonging to different size ranges - $R_{1}(0.0-0.2 \mu \mathrm{m})$, $\mathrm{R}_{2}(0.2-1.5 \mu \mathrm{m})$ and $\mathrm{R}_{3}(>1.5 \mu \mathrm{m})$ were calculated using curve fitting method.

\section{RESULTS AND DISCUSSION}

\section{Application of heat treatments}

Al 6063 alloy samples subjected to solution treatment as shown in Figure 2 were age hardened at $190{ }^{\circ} \mathrm{C}$ for $135,180,225,270$ and $315 \mathrm{~min}\left(\mathrm{t}_{\mathrm{x}}\right)$ to study the variation of precipitate size and size distribution and its effect on hardness. Parameters of the heating cycle were decided based on the pseudo-binary phase diagram of Al 6063 alloy in Figure 3 (Asensio-Lozano et al., 2014).

\section{Microstructure examination and identification of precipitate types}

Heat treated specimens of five different heating profiles were then transferred to microstructure examination. SEM images captured from specimens showed that particles with various sizes were distributed in the matrix ( $\alpha$ phase) as shown in Figure 4.

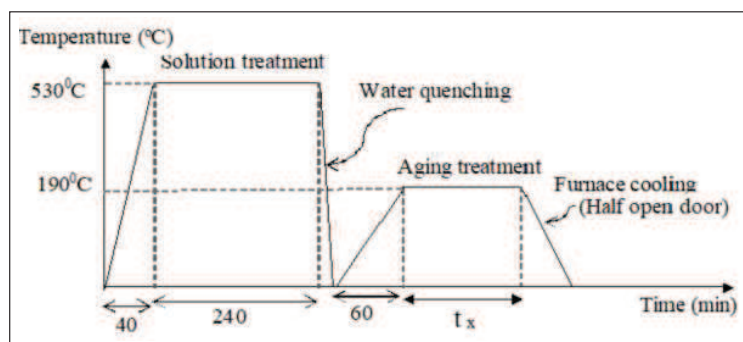

Figure 2: Heat treatment cycle applied to Al 6063 alloy samples

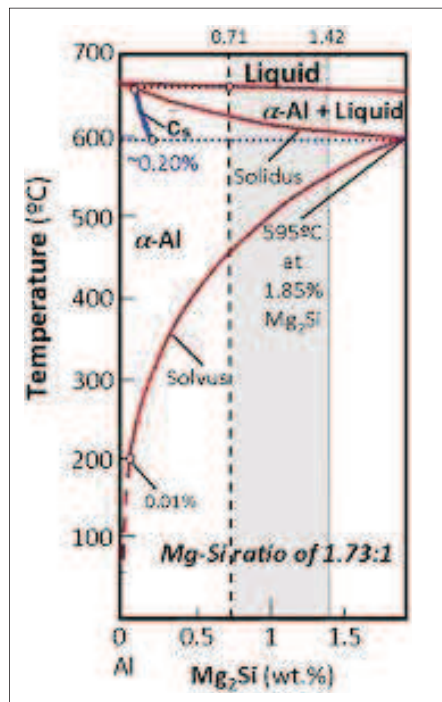

Figure 3: Pseudo-binary phase diagram for Al 6063 alloy

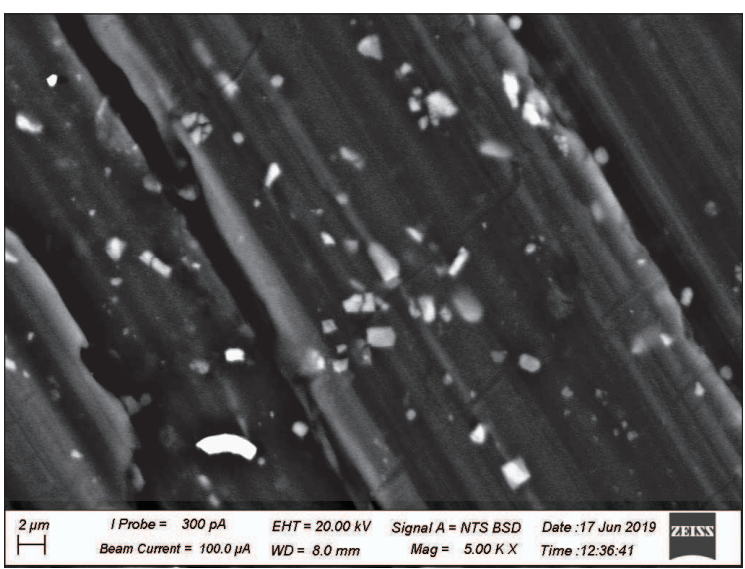

Figure 4: Al 6063 alloy solution treated at $530{ }^{\circ} \mathrm{C}$ for 4 hours, quenched in water and aged at $190{ }^{\circ} \mathrm{C}$ for 180 minutes 
In this work, identification of the precipitate/particle types were carried out irrespective of ageing time periods. Ten SEM images were selected from each specimen set related to different ageing times for SEM/EDS analysis of precipitates to ensure their chemical composition in terms of $\mathrm{Mg} / \mathrm{Al}, \mathrm{Si} / \mathrm{Al}$ and $\mathrm{Fe} / \mathrm{Al}$ weight ratios. Element weight ratio relative to the $\mathrm{Al}$ content is calculated inside and outside the particles (background/matrix). Two types of precipitates were identified as $\mathrm{Si}-\mathrm{Fe}$ rich and $\mathrm{Mg}$ $\mathrm{Si}-\mathrm{Fe}$-rich precipitates based on the above-mentioned

Table 2: Element weight ratios based on EDS results of Figure 5

\begin{tabular}{lcc}
\hline $\begin{array}{l}\text { Element weight ratio } \\
(\text { element/Al }) \times 100 \%\end{array}$ & $\begin{array}{c}\text { Inside } \\
\text { particle }(5 \mathrm{a})\end{array}$ & $\begin{array}{c}\text { Inside } \\
\text { matrix (5b) }\end{array}$ \\
\hline $\mathrm{Mg} / \mathrm{Al}$ & 2.2 & 2.1 \\
$\mathrm{Si} / \mathrm{Al}$ & 4.2 & 0.5 \\
$\mathrm{Fe} / \mathrm{Al}$ & 11.5 & 0.0 \\
$\mathrm{Al}$ content & 84.8 & 97.5 \\
\hline
\end{tabular}

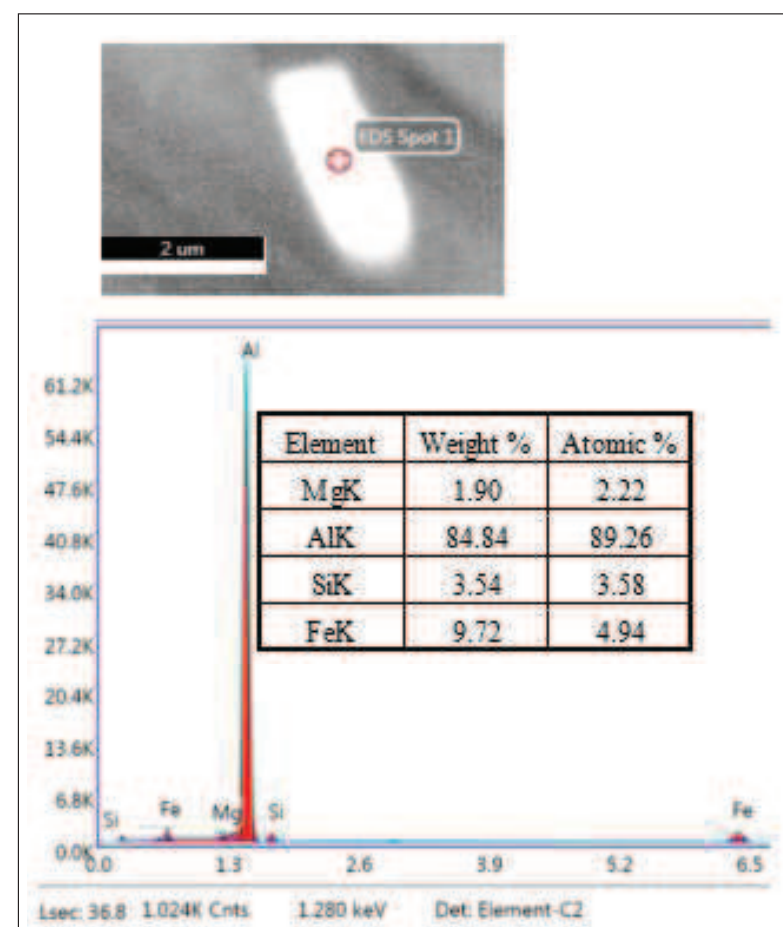

(a) analysis. The method of SEM/EDS analysis of these two precipitate types are explained as follows.

As per Table 2, it is obvious that $\mathrm{Si} / \mathrm{Al}$ and $\mathrm{Fe} / \mathrm{Al}$ element weight ratios are significantly higher inside the precipitates relative to the background. Therefore, it could be concluded that those are $\mathrm{Si}-\mathrm{Fe}$ rich precipitates. Likewise, based on the results shown in Table 3, those precipitates could be identified as $\mathrm{Mg}-\mathrm{Si}$-Fe-rich precipitates.

Table 3: Element weight ratios based on EDS results of Figure 6

\begin{tabular}{lcc}
\hline $\begin{array}{l}\text { Element weight ratio } \\
(\text { element/Al }) \times 100 \%\end{array}$ & $\begin{array}{c}\text { Inside } \\
\text { particle }(6 \mathrm{a})\end{array}$ & $\begin{array}{c}\text { Inside matrix } \\
(6 \mathrm{~b})\end{array}$ \\
\hline $\mathrm{Mg} / \mathrm{Al}$ & 2.1 & 0.6 \\
$\mathrm{Si} / \mathrm{Al}$ & 6.0 & 1.1 \\
$\mathrm{Fe} / \mathrm{Al}$ & 26.1 & 1.3 \\
$\mathrm{Al}$ content & 74.5 & 97.5 \\
\hline
\end{tabular}

Figure 5: SEM/EDS results of (a) inside and (b) outside of the precipitate formed under ageing at $190{ }^{\circ} \mathrm{C}$ for 135 minutes 
These types of second phase particles in age hardened $\mathrm{Al}$ 6063 alloy had been identified by previous researchers. Precipitates such as $\beta-\mathrm{Al}_{5} \mathrm{FeSi}, \mathrm{Al}_{15}(\mathrm{Mn}, \mathrm{Fe}) 3 \mathrm{Si}$ and $\pi-\mathrm{Al}_{8} \mathrm{Mg}_{3} \mathrm{FeSi}_{6}$ were identified by Kliauga et al. (2008) as precipitate colonies and they further revealed some
Fe-rich precipitates. Both Si-rich and Fe-rich precipitates were investigated by Ma et al. (2008). Moreover, they have studied the influence of precipitate types on mechanical properties of Al 6063 alloy.

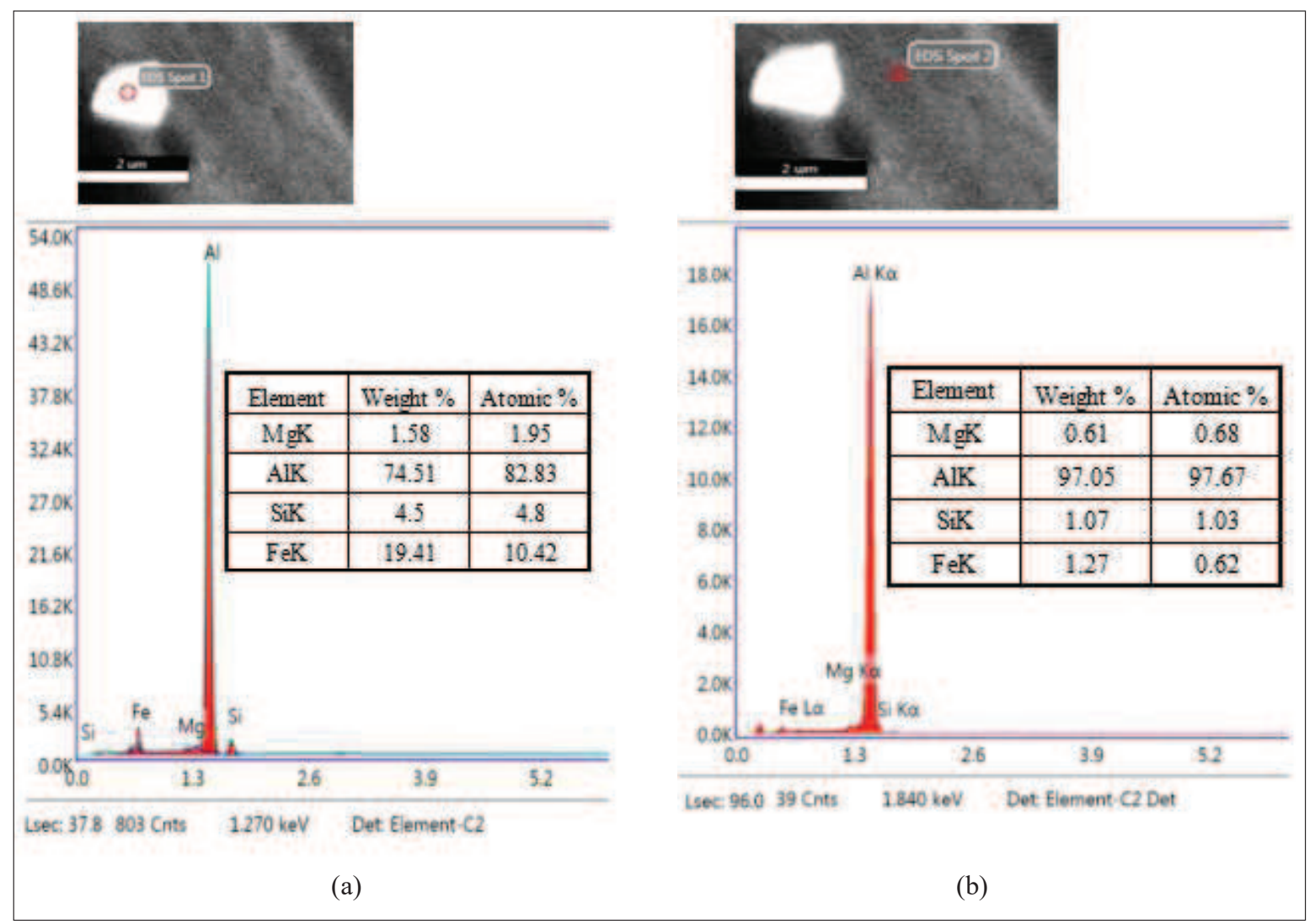

Figure 6: SEM/EDS results of (a) inside and (b) outside of the precipitate formed under ageing at $190{ }^{\circ} \mathrm{C}$ for 315 minutes

\section{Analysis of precipitate size and their distribution}

SEM images comprising distributed particles were analysed using Image $\mathrm{J}$ (Image Processing and Analysis in Java) software.

Each image was scaled and duplicated to relevant specific areas $(50 \mu \mathrm{m} \times 30 \mu \mathrm{m})$, and thresholded (Figure 7). All the sets of selected images for each ageing time period were analysed as shown in Figures 7 and 8. Average number of particles, their sizes and percentage of area covered by particles per specific area
$(50 \mu \mathrm{m} \times 30 \mu \mathrm{m})$ were calculated for each ageing time period, and the results are summarised in Figure 9.

\section{Effect of precipitate size distribution on hardness}

As shown in Figure 9, for the ageing time of $315 \mathrm{~min}$, average size of particles is increased while the average number and percentage of area covered by precipitates are reduced, relative to the variation occurred from 135 to $270 \mathrm{~min}$. This behaviour could have possibly occurred due to the phenomenon of overageing; that is coarsening of precipitates beyond a certain limit, absorbing dissolved 


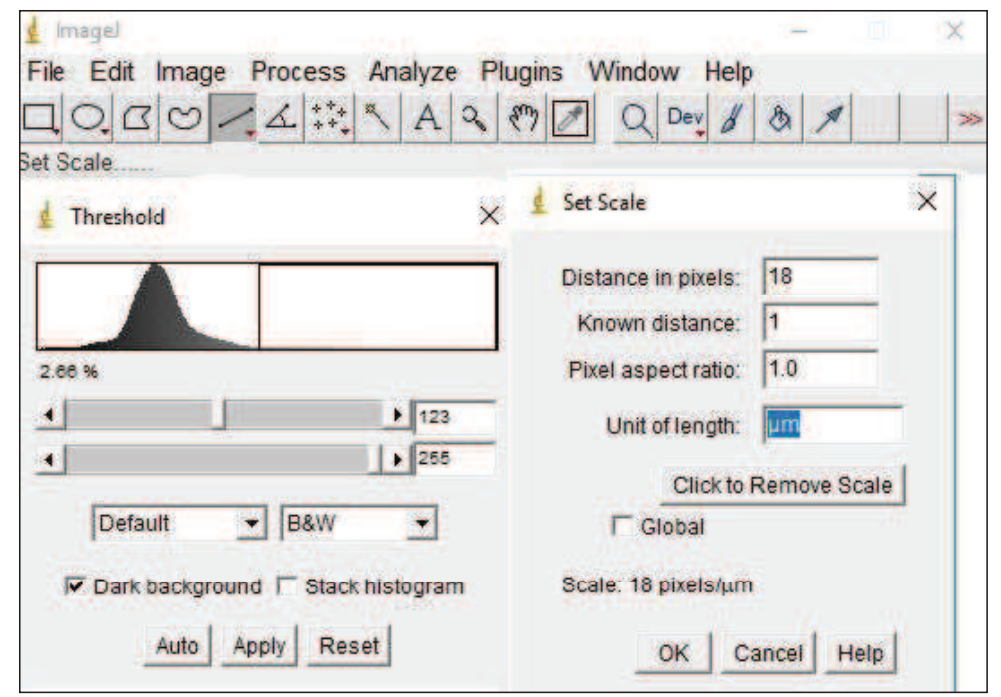

Figure 7: Image J- thresholding and scale functions

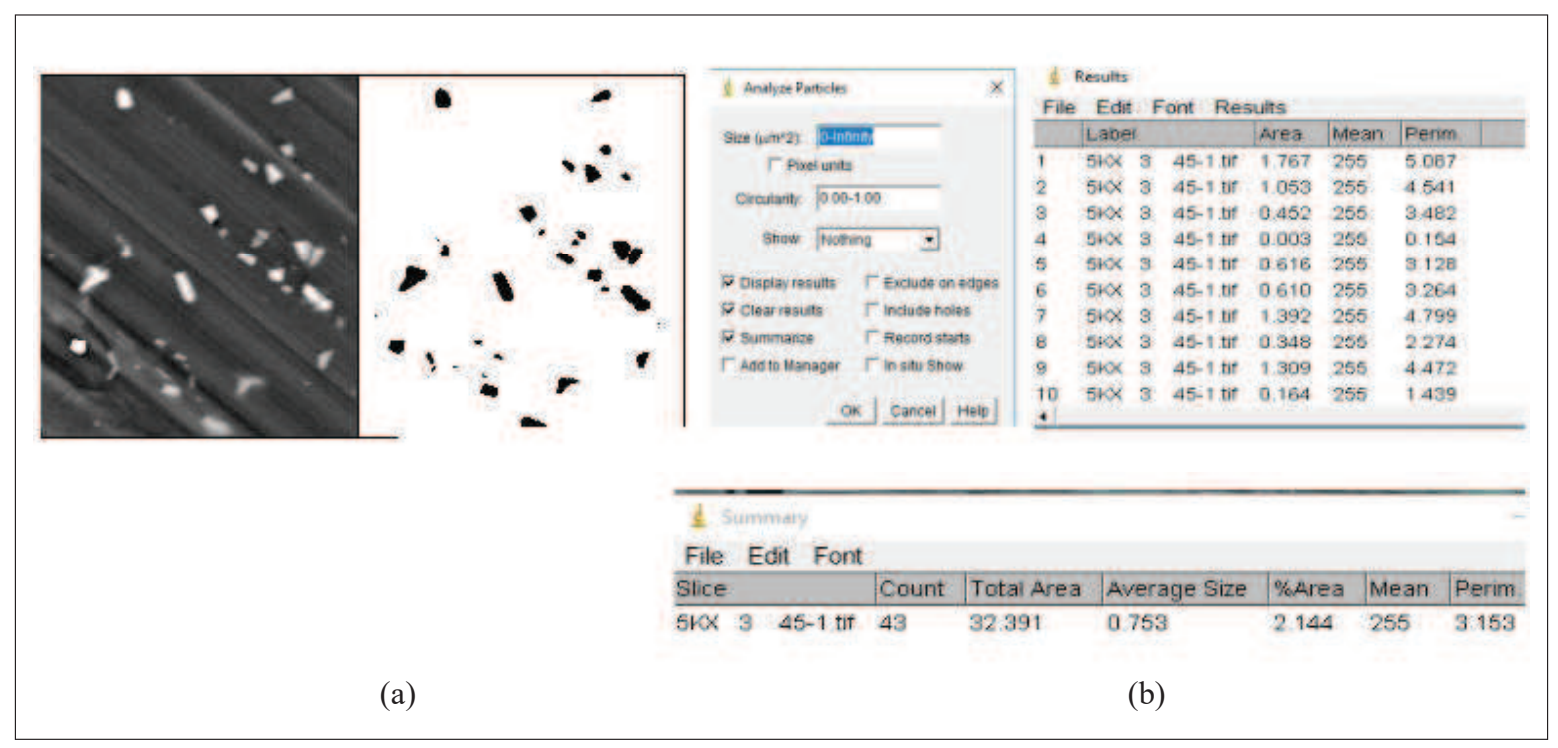

Figure 8: (a) Original and thresholded SEM image of a specimen age hardened for $135 \mathrm{~min}$; (b) data analysis procedure

small meta-stable precipitates. These coarsened particles lead to the development of highly stressed areas in particle-matrix interface, and further this phenomenon leads to the reduction of hardness and strength of the alloy sample. This explanation is justified by the reduction of hardness at 315 min while that is increased from 135 to $270 \mathrm{~min}$ (Figure 10). 


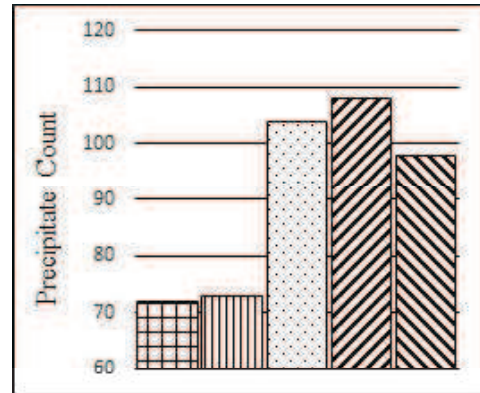

(a)

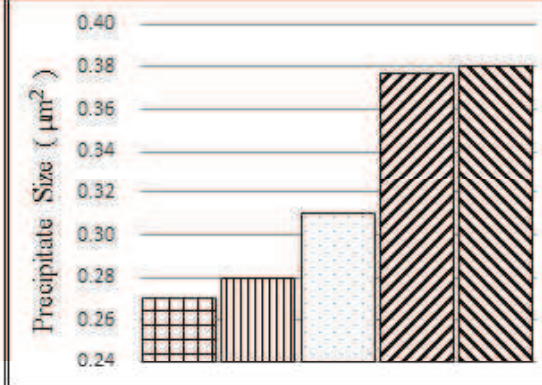

(b)

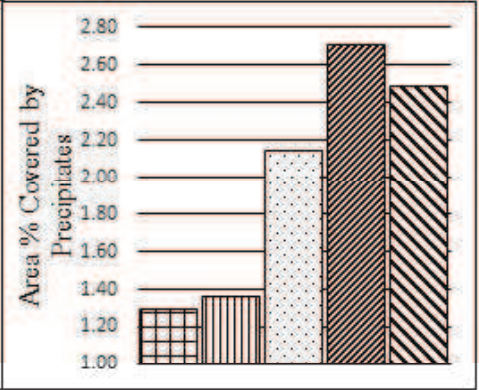

(c)

\section{\#135 min}

Figure 9: (a) Average number; (b) average size and (c) percentage of area covered by precipitates for specific area $(50 \mu \mathrm{m} \times 30 \mu \mathrm{m})$

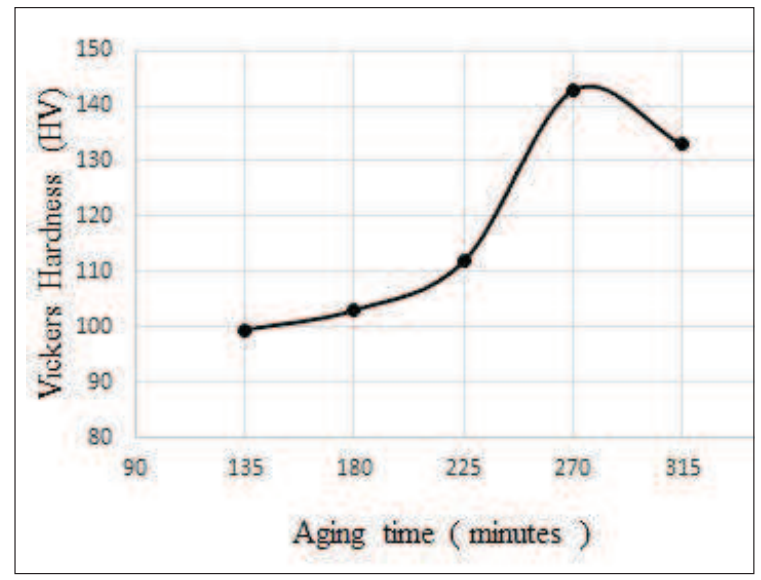

Figure10: Vickers hardness vs. ageing time

Table 4: Vickers hardness of samples aged at different ageing times

\begin{tabular}{cr}
\hline Ageing time (minutes) & HV \\
\hline 135 & 99.4 \\
180 & 103.0 \\
225 & 112.9 \\
270 & 143.9 \\
315 & 133.0 \\
\hline
\end{tabular}

Table 5: Percentage of particles in different size ranges

\begin{tabular}{lccc}
\hline $\begin{array}{l}\text { Ageing time } \\
\text { (minutes) }\end{array}$ & $\begin{array}{c}0.00-0.2 \mu \mathrm{m} \\
\mathrm{R} 1\end{array}$ & $\begin{array}{c}0.2-1.5 \mu \mathrm{m} \\
\mathrm{R} 2\end{array}$ & $\begin{array}{c}1.5 \mu \mathrm{m}< \\
\mathrm{R} 3\end{array}$ \\
\hline 135 & 51.0 & 43.8 & 5.2 \\
180 & 56.4 & 38.6 & 5.0 \\
225 & 66.0 & 29.5 & 4.5 \\
270 & 51.5 & 46.8 & 1.7 \\
315 & 50.7 & 42.7 & 6.6 \\
\hline
\end{tabular}

The initial increase in hardness occurred due to the hindrance of dislocation by precipitates formed during ageing treatment, especially precipitate size (diameter) up to around $1.5 \mu \mathrm{m}\left(\mathrm{R}_{1}+\mathrm{R}_{2}\right)$ as explained under the introduction. The percentage of precipitates belonging to each range $\left(R_{1}, R_{2}\right.$ and $\left.R_{3}\right)$ was calculated using a cumulative curve by curve fitting method and the results are summarised in Table 5.

According to the theories and available reports of hardening mechanisms (Jacobs et al.,1999; Kulkarni et al., 2004), the combination of cutting through, and 'bowing and bypassing' mechanisms play a major role for getting a significant improvement of hardness in Al 6063 within the particle size ranges of $\mathrm{R}_{1}$ and $\mathrm{R}_{2}$ (Cavazos \& Colãs, 2003; Nandy et al., 2015). Concluding all remarks, hardness vs percentage of precipitates belonging to ranges of $R_{1}$ and $R_{2}$ were plotted as shown in Figure 11 . 


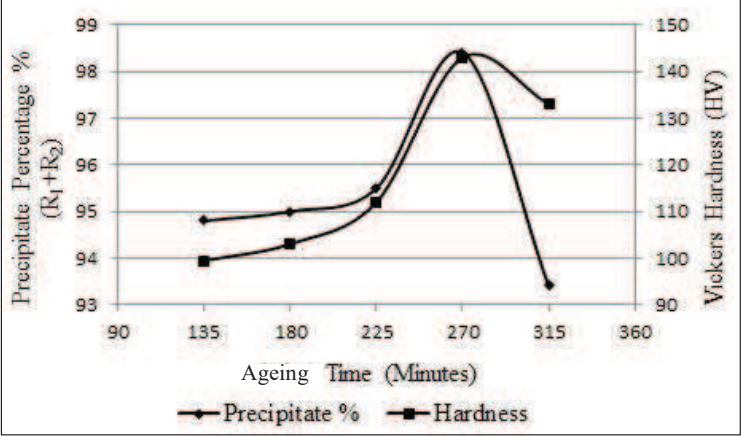

Figure 11: Variation of percentage of precipitates within $\left(R_{1}+R_{2}\right)$ and hardness with ageing time

As shown in Figure 11, percentage of precipitates within the particle size range of $\left(\mathrm{R}_{1}+\mathrm{R}_{2}\right)$ increased up to an ageing time of $270 \mathrm{~min}$ and a continuous increase of hardness is obtained accordingly. The highest percentage of precipitates within $\left(R_{1}+R_{2}\right)$ is $98.3 \%$ and the maximum hardness of 143.9 HV was recorded at an ageing time of $270 \mathrm{~min}$ (Figure 11). Moreover, at the ageing time of 315 min, a significant increase of percentage of precipitates above $1.5 \mu \mathrm{m}\left(\mathrm{R}_{3}\right)$, that is $6.6 \%$, was recorded relative to the ageing time $135-270 \mathrm{~min}$ (Table 5). Therefore, this reduction of hardness at the ageing time of $315 \mathrm{~min}$ could have occurred due to the phenomenon of overageing. The significance of this study is the experimental results shown in Figure 11 clearly explaining the variation of hardness of Al 6063 alloy with the precipitate size distribution in different ranges, under the increase of ageing time.

\section{CONCLUSION}

SEM/EDS examination showed that secondary phase precipitates formed at all heating profiles belong to two types of precipitates, as $\mathrm{Si}-\mathrm{Fe}$ rich and $\mathrm{Mg}$-Si-Fe-rich precipitates.

Percentage of precipitates within the particle size range of $0.0-0.2 \mu \mathrm{m}\left(R_{1}\right)$ and $0.2-1.5 \mu \mathrm{m}\left(R_{2}\right)$ increased up to the ageing time of 270 minutes and the increase of hardness occurred accordingly. The highest percentage of precipitates within $\left(R_{1}+R_{2}\right)$ is $98.4 \%$ and the maximum hardness of $143.9 \mathrm{HV}$ was recorded at the ageing time of $270 \mathrm{~min}$. Moreover, at this point, percentages of precipitates belong to three different size ranges were $51.5 \%, 46.8 \%$ and $1.7 \%$ for $0.0-0.2 \mu \mathrm{m}\left(\mathrm{R}_{1}\right), 0.2-1.5$ $\mu \mathrm{m}\left(\mathrm{R}_{2}\right)$ and above $1.5 \mu \mathrm{m}\left(\mathrm{R}_{3}\right)$, respectively.
A significant decrease in hardness was evident when the particles are coarsening above $1.5 \mu \mathrm{m}$, possibly due to overageing, for the ageing time beyond 270 minutes. At $315 \mathrm{~min}$, percentage of precipitates above $1.5 \mu \mathrm{m}$ is $6.6 \%$ which is a significant increase relative to the ageing time of 135-270 min.

This study clearly explains the variation of hardness of Al 6063 alloy with precipitate size distribution in different ranges, with the increase of ageing time.

\section{Acknowledgement}

The authors thank the academic and non-academic staff of the Department of Materials Science and Engineering, University of Moratuwa and the Senate Research Council (SRC/ST/2018/27) grant of University of Moratuwa for financial assistance. The authors also acknowledge Alumex (Pvt) Ltd. for providing samples and technical assistance.

\section{REFERENCES}

Asensio-Lozano J., Suárez-Peña B. \& Voort G.F.V. (2014). Effect of processing steps on the mechanical properties and surface appearance of 6063 aluminium extruded products. Materials 7(6): 4224-4242.

DOI: https://doi.org/10.3390/ma7064224

Cavazos J.L. \& Colás R. (2003). Quench sensitivity of a heat treatable aluminium alloy. Materials Science and Engineering A 363(1-2): 171-178.

DOI: https://doi.org/10.1016/S0921-5093(03)00616-6

Couper M.J. (2010). Selecting the optimum Mg and Si content for 6 xxx series extrusion alloys. Proceedings of the $12^{\text {th }}$ International Conference on Aluminium Alloys, September 5-6, Yokohama, Japan, The Japan Institute of Light Metals, pp. 149-154.

Gao R., Stiller K., Hansen V., Oskarsson A. \& Danoix F. (2009). Influence of ageing conditions on the microstructure and tensile strength of aluminium alloy 6063. Materials Science Forum 396-402: 1211-1216.

DOI: https://doi.org/10.4028/www.scientific.net/msf.396402.1211

Guo Z. \& Sha W. (2005). Quantification of precipitation hardening and evolution of precipitates. Materials Transactions 43(6): 1273-1282.

DOI: https://doi.org/10.2320/matertrans.43.1273

Jacobs M.H. (1999). 1204 Precipitation hardening. TALAT Lecture. The University of Birmingham, UK

Kliauga A.M., Vieira E.A. \& Ferrante M. (2008). The influence of impurity level and tin addition on the ageing heat treatment of the 356 class alloy. Materials Science and Engineering A 480(1-2): 5-16.

DOI: https://doi.org/10.1016/j.msea.2007.07.091

Kulkarni A.J., Krishnamurthy K., Deshmukh S.P. \& Mishra 
R.S. (2004). Effect of particle size distribution on strength of precipitation-hardened alloys. Journal of Materials Research 19(9): 2765-2773.

DOI: https://doi.org/10.1557/jmr.2004.0364

Li H.Y., Zeng C.T., Han M.S., Liu J.J. \& Lu X.C. (2013). Time-temperature-property curves for quench sensitivity of 6063 aluminium alloy. Transactions of Nonferrous Metals Society of China (English Edition) 23(1): 38-45. DOI: https://doi.org/10.1016/S1003-6326(13)62426-7

Lifshitz I.M. \& Slyozov V.V. (1961). The kinetics of precipitation from supersaturated solid solutions. Journal of Physics of Chemistry of Solids 19: 35-50. DOI: https://doi.org/10.1016/0022-3697(61)90054-3

Lillywhite S.J., Prangnell P.B. \& Humphreys F.J. (2012). Interactions between precipitation and recrystallisation in an Al-Mg-Si alloy. Materials Science and Technology 16(10): 1112-1120.

DOI: https://doi.org/10.1179/026708300101507037

Ma Z., Samuel A.M., Samuel F.H., Doty H.W. \& Valtierra S. (2008). A study of tensile properties in Al-Si-Cu and AlSi-Mg alloys: effect of $\beta$-iron intermetallics and porosity. Materials Science and Engineering A 490(1-2): 36-51.
DOI: https://doi.org/10.1016/j.msea.2008.01.028

Mohles V., Rönnpagel D. \& Nembach E. (1999). Simulation of dislocation glide in precipitation hardened materials. Computational Materials Science 16(1-4): 144-150. DOI: https://doi.org/10.1016/s0927-0256(99)00056-7

Nandy S., Kumar K. \& Das D. (2015). A process model to predict yield strength of AA6063 alloy. Materials Science and Engineering A 644(October 2017): 413-424.

DOI: https://doi.org/10.1016/j.msea.2015.07.070

Siddiqui R.A., Abdullah H.A. \& Al-Belushi K.R. (2000). Influence of ageing parameters on the mechanical properties of 6063 aluminium alloy. Journal of Materials Processing Technology 102(1): 234-240.

DOI: https://doi.org/10.1016/S0924-0136(99)00476-8

Sjölander E. \& Seifeddine S. (2010). The heat treatment of Al$\mathrm{Si}-\mathrm{Cu}-\mathrm{Mg}$ casting alloys. Journal of Materials Processing Technology 210(10): 1249-1259.

DOI: https://doi.org/10.1016/j.jmatprotec.2010.03.020

Yıldırım M. \& Özyürek D. (2013). The effects of Mg amount on the microstructure and mechanical properties of $\mathrm{Al}-\mathrm{Si}$ Mg alloys. Materials and Design 51(2013): 767-774. DOI: https://doi.org/10.1016/j.matdes.2013.04.089 